\title{
ON DETERMINING THE OPTIMAL MAGNITUDE AND LENGTH OF LIABILITY IN TORTS
}

\author{
DANIEL L. RUBINFELD*
}

I

N"Tort Reform and the Role of Government in Private Insurance Markets," Patricia Danzon argues that it is probable that the size of damage awards is inefficiently high and the period in which defendants are exposed to liability unduly long. Her paper represents an impressive effort, because of the scope and detail of its analysis. ${ }^{1}$ The paper builds heavily on the recent literature on the economic analysis of law and is written in that spirit. The "new" law and economics is to be distinguished in part by its focus on the common law, but also for its devotion to the formal model-building process. Model building has the advantage of forcing the writer to lay out the logic of the argument clearly and to make assumptions explicit. The approach also has its risks. Models may be unnecessarily simplified in order to be mathematically tractable, and undiscerning readers may be tempted to read stronger policy implications into the analysis than is justified. Danzon's paper illustrates, in my view, many of the benefits of model building as well as some of its dangers. The clarity of the model and its presentation allow a critical reviewer to make constructive suggestions for improvement. The weakness of the paper is that it invites the reader to draw rather strong policy conclusions from a model still in its formative stages.

The substantive theme of my comments is that the relationship between the design of tort reform and the costs of litigation is a subject area in need of substantially more attention in the law and economics literature. My analysis, like Danzon's, starts from two assumptions: (1) efficiency in liability rules is at least an important if not a dominant objective of the tort

\footnotetext{
* Professor of Law and Economics, University of California, Berkeley. I wish to thank Robert Cooter, Patricia Danzon, Gregory Call, and Steven Sugarman for their helpful comments. Many of the comments concerning the litigation process are based on joint work with David Sappington.

1 Patricia M. Danzon, Tort Reform and the Role of Government in Private Insurance Markets, in this issue.

[Journal of Legal Studies, vol. XIII (August 1984)]

(C) 1984 by The University of Chicago. All rights reserved. 0047-2530/84/1303-0002\$01.50
} 
system and (2) risk bearing is a relevant consideration if that goal is to be achieved. Following Danzon I will divide my comments into two sets. The first set deals with the size of awards, where her arguments closely track the law and economics literature. The second set addresses the statute of limitations and the more intriguing and complex issues it raises.

\section{The Optimal Size of Awards}

\section{Is the Distribution of Awards Optimal?}

Danzon tells us that a large portion of the cost of the tort system, at least in the medical malpractice area, is attributable to catastrophic awards. She finds in these costs two possible sources of inefficiency, neither strongly supported by empirical evidence. First, there may be too many suits of a questionable nature. Second, awards may be too large once liability is determined. Danzon advances some economic arguments and empirical evidence in support of her view. Her empirical evidence shows that the distribution of malpractice awards has become skewed over time with a relatively thick tail at the high end of the distribution. Danzon's notion is that the asymmetric distribution of malpractice awards is strong evidence of inefficiency. I am not convinced.

In my view, a sound analysis of the distribution of awards necessarily depends on the model that describes the generation of medical malpractice "accidents." If the distribution of harms caused by malpractice injuries is asymmetric, the additional costs in catastrophic cases, far from being a sign of overpayment and inefficiency, may better be understood as accurately describing the world-an efficient world at that ${ }^{2}$ How can one resolve the question whether a skewed award distribution is efficient? I have no easy answer. An appropriate theory is difficult to develop, in part because the shape of the distribution of actual awards depends on the choice of substantive legal rules, as they affect both the frequency of successful suits and the damage determinations. ${ }^{3}$

\section{Deterrence versus Compensation}

Danzon argues, in the spirit of the law and economics framework, that it is important to distinguish the deterrence charge from the efficient

\footnotetext{
2 The increase in claims frequency and awards filed over time may simply reflect a growing awareness of the availability of the tort remedy for medical malpractice. See Patricia Munch Danzon \& Lee A. Lillard, Settlement out of Court: The Disposition of Medical Malpractice Claims, 12 J. Legal Stud. 345 (1983) at 370-72 for some relevant evidence.

${ }^{3}$ For example, custom may not be a defense in malpractice cases in some jurisdictions, while it is a defense in others. The thick tail at the high end of the distribution may reflect the additional cases brought because of the lack of a custom defense. Whether this is efficient or not depends on one's evaluation of the substantive rule in this situation.
} 
amount of compensation. If there are two goals, then two instruments will be necessary to achieve efficiency. The efficient policy is to set compensation equal to the amount of insurance that a knowledgeable consumer would have purchased prior to the injurious event. ${ }^{4}$ While in principle the optimal amount of insurance could be greater than or less than the monetary losses involved, Danzon suggests that it would be less since the marginal utility of money is likely to be lower with disability than without. ${ }^{5}$ Danzon also suggests that the appropriate deterrence charge is greater than the efficient compensation level, implying that if all charges are paid to the victim, excessive insurance will be provided.

I find a number of troubling issues here. The first is that once one takes into account the victim's lawyer's fees and litigation costs, the amount of insurance desired gross of litigation costs could be larger, even substantially larger, than the full monetary damages. A second involves a criticism of the basic model, at least if its policy implications are to be taken seriously. Danzon's argument suggests a partial move away from the traditional tort system of awards, toward one where deterrence "surcharges" are paid to the state rather than to the victim. With sufficient information, the state could generate the appropriate incentives for potential injurers, without undermining the distinct compensation goals. But her economic model is deficient on a number of points. If money is paid to the state, the state perforce must act as tort plaintiff and incur the corresponding litigation costs. What incentives will the state have in such a situation? And how will it allocate the revenues it collects?

Perhaps the deterrence charge so collected should then be paid as compensation to the class of all persons injured by medical misadventures as well as medical malpractice, thereby serving some social goal of income redistribution or equity, but only with substantial administrative costs. Nonetheless, without a model of the role of the state in this process, I would be wary about reaching a definitive policy conclusion. ${ }^{6}$

The third difficulty is that Danzon's empirical evidence is weak in this

4 This would depend in part on the defendant's risk averseness.

5 This represents casual empiricism, not theory. It is quite possible that for many individuals the marginal utility of income would rise, since money may be the only object that stands between the individual and constant pain.

6 Finally, compensation itself could be based on factors other than immediate damages to the victim. Compensation for society's moral outrage associated with medical malpractice might be substantially greater than the insurance payment that would be made had private insurance been purchased. Or we could go further with this and argue that in the case of unintentional torts, at least, the state should view the compensation issue in the context of the broader subject of social insurance. The implicit notion would be that victims of unintentional torts are no different from the "victims" who are unlucky in being unable to find employment with adequate compensation. The state currently provides social insurance through a large number of programs, one of which is the progressive income tax system. 
area. It is quite possible that in the medical malpractice setting, effective deterrence may require extremely large damage awards. ${ }^{7}$ This might be true without insurance, and it becomes more likely where insurance is in place. My casual understanding is that insurance premiums respond only slightly to the determination of liability, and very little to the size of the award. This may well be sound insurance company policy if catastrophic awards are viewed essentially as random events. It might also be sensible if the infrequency of large damage awards leads to erratic results where rates are too heavily experience rated. Whatever the reason, if very large awards are used for deterrence purposes, the administrative costs can be very large and the allocative effects substantial. We must have better empirical evidence about the deterrence effects of civil damages before we draw definitive policy conclusions.

\section{The Importance of Litigation and Settlement Costs}

Let me focus my attention, however, on the instrumental role that damage payments can and should play in setting tort awards. I have no problem with making a distinction between deterrence charges and compensation, as Danzon and other economists would suggest. I would press the argument further, especially in the light of the questionable evidence about deterrence in the tort area. First, I would expand the model to take into account the "market for litigation" by assuming that the probability of litigation, conditional on the occurrence of an injury, increases with the magnitude of the damage award. The model would recognize explicitly that as the deterrence charge increases, litigation becomes more likely, regardless of whether the state or the victim collects.

A number of questions need to be resolved. Can the state sue to obtain deterrence charges or is a separate administrative process desirable? Do individuals recover by suing individual defendants or by requesting compensation from an administrative body? Whatever the choices, it should be clear that litigation involves real economic costs, including not only the costs of administering the judicial and/or administrative process, but also the costs associated with individuals diverting their time from productive

\footnotetext{
7 There may be substantial costs that make high damage awards inefficient. In a world of risk-averse injurers they may induce greater than efficient care in certain risky procedures, or they may induce physicians to avoid or abandon risky procedures entirely. This may explain why certain private contracts have damage provisions that are below actual losses. Large damages may discourage physicians from taking part in the process, but if they do, litigation expenses may grow more than proportionally with the size of the damage awards.
} 
activities toward litigation. As a result, it may be reasonable to set lower deterrence charges than the standard model might suggest. ${ }^{8}$

A second modeling problem arises because paying part or all of deterrence charges to the state instead of the victim is likely to affect the settlement process and the settlement-litigation choice in particular. The most obvious effect arises because the compensation arrived at during the negotiation process, based on the harm done to the plaintiff, is likely to be less than the deterrence charge to be paid if litigation occurs and liability is determined. Thus with a deterrence surcharge the private parties might have an incentive to settle rather than to litigate. It would be natural to consider the state as a party to the litigation whose rights cannot be settled out without its consent. The effects of a deterrence surcharge on settlement behavior may be further complicated. Under this system, the expectations of both private parties of the returns from litigation relative to settlement would change. Even though the total reward to the individual parties is larger in settlement than in litigation, it is not difficult to imagine cases in which one party seeks to win a larger share of a smaller pie through litigation. ${ }^{9}$ Whether any such change in settlement-litigation behavior improves economic efficiency seems to me to be a difficult question to evaluate. ${ }^{10}$ The possible efficiency gains or losses could be large and should be addressed before resolving the issue of deterrence charges.

Third, the choice of a deterrence charge as well as level of compensation will have important effects on the behavior in litigation, especially if the effort of the parties in litigation is sensitive to the size of the stakes. Whether the legal system should increase damages and encourage greater litigation depends on a court's ability to distinguish "innocent" from "guilty" parties when both are expending substantial sums of money."

\section{The Scheduling of Awards}

Danzon's paper is especially interesting because it presents empirical evidence, much of it casual, about the appropriate form of damage

\footnotetext{
8 In the final analysis the optimal deterrence charge in such a "rent-seeking" world would depend on the kinds of litigation that arise and whether such litigation is brought by "innocent" or "guilty" parties.

${ }^{9}$ For an interesting discussion and empirical analysis of the settlement-litigation decision, see George L. Priest \& Benjamin Klein, The Selection of Disputes for Litigation, $13 \mathrm{~J}$. Legal Stud. 1 (1984).

10 The answer clearly depends crucially on the objectives of the litigation process and on empirical information about who is likely to settle and who is likely to litigate.

11 This argument is based on the analysis in Daniel L. Rubinfeld \& David Sappington, On the Optimal Design of the Court System (1983)(unpublished manuscript, Univ. Calif., Berkeley, Law School, and Univ. Pa., Dep't Economics).
} 
awards. Basing her argument in part on the empirical evidence, Danzon proposes that awards should be scheduled and suggests that tort law is unsound in providing for unique awards for individual plaintiffs. She claims that the tort system is prey to moral hazard because a plaintiff stands to gain substantial benefit by presenting a particularly effective case. Her view is that we ought generally to view litigation costs as socially wasteful, insofar as they contest the award size.

The important questions now are $(a)$ whether a scheduling of awards will reduce litigation expenditures and $(b)$, if expenditures are reduced, whether social welfare is thereby increased. Neither proposition seems intuitively clear. Consider the possibility that the plaintiff's litigation effort can convince the court to make a higher award-here litigation and scheduled award are joint products. Or consider the possibility that the proposed schedule overcompensates for certain injuries. In both cases plaintiff expenditures should increase, and defense expenditures should respond accordingly. Even if expenditures are reduced, an unambiguous gain in social welfare will only occur if it can be shown that society will make fewer type 1 or type 2 errors. (Type 1 errors occur when nonnegligent parties are punished and type 2 errors occur when negligent parties are held not liable.) The result is not obvious. ${ }^{12}$

All of these arguments are, of course, sensitive to the particular form of scheduling that is used. In workers' compensation, for example, awards are scheduled, but depend in part on the average weekly wage of the worker. In other forms of tort awards, the compensation is dependent on the particular nature of the harm done. Regardless of content, scheduled awards are best understood as an uneasy compromise between an administratively simple but inaccurate fixed award, and an administratively difficult but potentially accurate system of case-by-case awards.

Danzon also asserts that scheduling eliminates the undesirable risk that the individualization of awards otherwise introduces into tort cases. The difficulty with this argument lies with the nature of the "risk" involved. If the variance of awards is random and uncorrelated with either the care taken by the injurer or the victim's injury, then her argument has some force. Variance and risk are now equivalent, so that the reduction of risk faced by risk-averse parties enhances efficiency. However, if the variance is systematically and reasonably related to care, and thus to fault, then variance is a good thing, since it generates the right set of individual incentives. On this view, individuals do not face additional risk, even though the distribution of awards has a high variance. The problem lies in

${ }^{12} I d$. 
defining the relevant universe within which one is to talk about randomness.

Finally, I should add that in some situations randomness can improve welfare, even in a world of risk-neutral individuals. If the randomness of awards alters the behavior of plaintiff and defendant to decrease the marginal productivity of effort by negligent parties, while increasing (at least relatively) the marginal productivity of effort by nonnegligent parties, then randomness adds to social welfare by making the legal process efficient. ${ }^{13}$

\section{Explaining the Effort of Plaintiffs and Defendants}

In arguing for the scheduling of awards, Danzon raises an intriguing empirical issue. She points out on the basis of previous work that the more severe the injury the smaller the ratio of defense expenditures to plaintiff expenditures in litigation. She states that this is consistent with a relatively rapid decline in defense-expenditure productivity and that this propensity becomes especially apparent when the defendant is a corporation or an insurance company.

A suitable theory to explain this empirical fact could help us to understand the litigation process and eventually to answer the question whether damage awards are inefficiently high. One possible speculation, which might apply to corporations or insurance companies, focuses on the different incentives that the parties face. Insurance companies, unlike plaintiffs, are frequently involved in repeat litigation. ${ }^{14}$ They also view unusually high awards as random events that are not very sensitive to moral hazard on the part of plaintiffs. Being repeat litigation players, they stress efforts to reduce the plaintiffs' probability of victory in future cases where they can win on a point of law. Any small decrease in probability can lead to a substantial decline in the present value of all future tort liability awards.

Of course, some types of defense effort go to the facts of the case and not to the points of law. Factual defenses may reduce the magnitude of the award in any one particular case, yet overall they are unlikely to be as productive, because they have little or no precedential effect. Where

13 This might happen, for example, if innocent parties were more risk averse than guilty parties, a reasonable assumption if one is willing to believe that risk-averse individuals tend not to commit crimes in the first place.

14 In some cases there will be repeat players on the plaintiff's side as well. For example, a contingent fee lawyer whose fee is a function of the size of the settlement may represent plaintiffs frequently. If the structure of legal rules can be changed, there can be substantial gains. In fact, trade associations exist that finance test cases that have precedential value and also write amicus briefs in important appellate cases. 
there are common fact patterns, as in asbestos cases, it might pay to invest heavily in factual determinations. However, it is the uniqueness of individual fact patterns that often distinguishes medical malpractice from product liability cases, thereby creating a substantial sociolegal risk on fact issues only in product cases.

Whether the arguments just made will support the empirical facts that Danzon describes will depend not only on the differing incentives of the parties but also on the relative productivity of their efforts. I have no strong empirical basis for suggesting that this argument is correct, but if it is, it undercuts Danzon's view that large awards in serious cases are socially suboptimal. ${ }^{15} \mathrm{~A}$ simple model which spells out the arguments in some detail is presented in the Appendix to this paper.

\section{The Statute of Limitation}

Danzon is disturbed about the long periods in which damage actions can be maintained in products liability and medical malpractice cases. She argues that the modern law on the limitation of actions fails to take into account the insurance risks posed by the long periods open for suit. One of these might be the risk that society will change the standard of care in negligence cases. A second risk might be that the statute itself will be changed. Danzon argues that this kind of risk-essentially, that commonlaw rules will change over time-cannot be eliminated by the usual riskspreading methods. One might be tempted to argue that capital markets allow for the spreading of such risk, but I doubt that this is possible. Should we, therefore, shorten the statute of limitation in order to diminish this risk? If so, how do we determine its optimal length?

In order to evaluate the efficient statute length, one must first consider the explicit objectives that the statute serves. Presumably one major purpose is evidentiary. As time passes, either from the time of injury or the date of manifestation, the evidence needed for litigation deteriorates in quality: witnesses' memories tend to fade, and technical or medical information becomes less reliable. Danzon's argument about uncertainty supports the proposition that statutes should be shorter, just as the evidentiary argument does. Considerations of justice might provide support for the longer periods.

The important questions that remain unanswered are the following. First, do the evidentiary and risk arguments conflict with each other or are they independent? Second, were considerations of risk made when the current statute lengths were determined? Without having answers to

15 The answer will depend on the differential incentives faced by plaintiffs and defendants. It will also depend on the game-theoretic behavior of the parties, but this is an issue too complex to be incorporated easily into the analysis. 
these questions, it is difficult to evaluate whether statute lengths ought to be shortened. Since the evidentiary issues seem to me to be only indirectly related to Danzon's immediate concern with "crushing" tort liability, the danger is that we might throw out, or severely limit, the use of tort actions in order to obtain some (marginal) gain of reduced uncertainty. ${ }^{16}$ What other policy instruments can be utilized to handle the evidentiary issues? And what will be the efficiency loss if the statute of limitation is shortened?

I have no doubt that Danzon's risk argument is an important one. To the extent that common-law rules change over time, uncertainty is generated that cannot be eliminated by the usual risk-pooling methods. A portion of that difficulty arises simply because individuals cannot be sure what standard of care will be applied if a case is litigated. Obviously, this knowledge problem would be eliminated in theory by using as a standard the best available state-of-the-art technology at the time of the injury. But in practice there is sufficient uncertainty about what that standard will be and about whether the legal rule itself will change. The ideal solution is not terribly helpful. Danzon's argument that the risks of change in and misapplication of legal rules are likely to be correlated among policyholders and not diversifiable seems to me to be correct, although others might disagree. ${ }^{17}$

Where the argument takes us is less clear. One could argue, for example, that the longer the statute of limitation, the more likely it is that injurers will be sued for harms that they have caused. The efficiency loss attributable to uncertain rules must therefore be balanced against the gain in increased deterrence. Danzon suggests that with sufficient uncertainty, deterrence incentives will disappear, but this branch of her argument is not developed in the paper. I would want to balance the deterrence gains against the efficiency losses due to uncertainty that naturally arise when risk-averse potential injurers must bear risk.

I suspect that one could utilize Danzon's argument or its converse to make a strong case for a longer statute of limitation on deterrence grounds. Assuming risk-averse injurers, greater risk may stimulate additional care by the injurers. Whether such additional care is efficiency enhancing is unclear, but one could make an argument that it is. ${ }^{18}$ Assume, for example, that the probability of harm is so low that the efficient

\footnotetext{
16 The question is whether the ability to purchase a broad set of securities allows this risk to be spread-a strong assumption, in my view.

17 In the end the correct analysis involves a second-best comparison of a shortening of the statute of limitation and other possible second-best policies.

${ }^{18}$ I am not convinced, however, by her argument that the statute of limitation will bring about intergenerational inefficiencies. It seems to me that the arguments made involve distributional changes without efficiency implications.
} 
penalty for deterrence would bankrupt the firm or injurer. The added uncertainty associated with the lengthy statute of limitation could act as a kind of second-best policy instrument for deterrence purposes.

\section{Conclusion}

The application of the tools of economics to the study of legal problems is still at a relatively primitive state, especially when both empirical and theoretical methods are combined. Danzon's paper is to be commended, as it attempts to treat empirical and theoretical questions jointly. I have tried to suggest some difficulties that are raised by Danzon's arguments and to indicate where further research on the costs of litigation and the litigation process might provide important new insights, both theoretical and practical.

\section{APPENDIX \\ On the Divergence between Plaintiff and Defendant Interests}

Plaintiffs in tort litigation are often single players, in the sense that they are unlikely to litigate often, especially against the same defendant. (This might not be true in automobile accident situations, for example, in which both the injurers and victims are insured.) Defendants, on the other hand, are often repeat players, since they may be defending against multiple claims associated with the same injury or against different alleged injuries over time. As a result, defendants realize in deciding on their defense effort that expenditures on defense can not only affect the probability of winning a particular case, but can also give a signal to potential litigants about the defense effort to be made in future cases. This signal could reduce the probability that future litigation is brought. Since the present discounted value of the future damage payments can be large, any small reduction in the probability of litigation can have substantial benefits for the defendant.

Whether this divergence of interests can explain why the ratio of defense expenditures to plaintiffs' expenditures falls with the magnitude of the damages involved depends not only on the different incentives, but also on the possibility that litigants will have different marginal productivities of expenditures. The following simple model sketches how the different objectives and different marginal productivities of the parties can influence their relative expenditures. The model has been intentionally pared down to its simplest form, but the assumptions are spelled out to illustrate the nature of the direction that a more comprehensive model of the litigation process might take.

\section{Assumptions}

1. The current litigation involves a single plaintiff and a single defendant.

2. Transactions costs are such that negotiation and settlement are not possible.

3. Effort made during the litigation can be proxied by the level of expenditures made during litigation.

4. Plaintiffs and defendants base their decisions on their subjective (or perceived) probability of winning the case as a function of their own effort. These 
decisions are made independently of one another. (This rather strong assumption should be relaxed to allow for game-theoretic behavior.)

5. Plaintiffs and defendants are both risk neutral. (This assumption is not necessary, but it greatly simplifies the analysis.)

\section{Definitions}

$e^{1}=$ expenditures by the plaintiff.

$e^{2}=$ expenditures by the defendant.

$p\left(e^{1}\right)=$ subjective probability of the plaintiff's winning the case, with the court determining that the injury has taken place.

$P\left(e^{2}\right)=$ subjective probability of the defendant's losing the case (not necessarily equal to $p\left(e^{1}\right)$.

$D=$ damages to be paid if defendant is assumed to be negligent.

$F\left(e^{2}\right)=$ probability that future cases involving alleged plaintiff injuries will be litigated and won by plaintiff.

$V=$ value of future litigation damages discounted over time.

The assumption that $D$ is fixed is reasonable in a world in which litigation effort is directed toward winning the case, but not toward affecting the damage level itself. Note that the $F(\quad$ ) function comprises two components, the probability that litigation will be brought and the probability that litigation will be lost by the defendant. Both probabilities are likely to be inverse functions of $e^{2}$ in ways that are quite complex. I have omitted these complications to simplify the presentation. For the same reason $V$ is assumed to be fixed, an assumption which rules out the possibility that future litigation can affect the damage level and does not include future expenditures by defendant as a cost.

\section{Additional Assumptions}

$p_{1}=$ derivative of $p()$ with respect to $e^{1} ; p_{1}>0, p_{11}<0$.

$\boldsymbol{P}_{2}=$ derivative of $P()$ with respect to $e^{2} ; P_{2}<0, P_{22}>0$.

$F_{2}=$ derivative of $F()$ with respect to $e^{2} ; F_{2}<0, F_{22}>0$.

The assumptions concerning the derivatives of the $p()$ and $\left.P()^{\prime}\right)$ functions imply that expenditures of both parties have diminishing marginal productivity, but no assumption is made about the relative magnitude of the marginal productivities themselves.

\section{Objectives of the Parties}

The objective of the plaintiff is to maximize expected damages net of litigation costs. The objective of the defendant is to minimize the sum of expected damages paid during the current litigation, expected litigation costs, and the expected present discounted value of future litigation expenses.

Optimization of the plaintiff:

$$
\max p\left(e^{1}\right) D-e^{1},
$$

with the first-order condition

$$
p_{1} D=1
$$

Optimization of the defendant:

$$
\min P\left(e^{2}\right) D+F\left(e^{2}\right) V+e^{2}
$$


with the first-order condition

$$
P_{2} D+F_{2} V=1 \text {. }
$$

With this background we can prove a few general results and then, with the aid of choice of functional form, a few specific results concerning the relative levels of effort made by plaintiffs and by defendants.

THEOREM 1: If plaintiff's marginal productivity of expenditures is higher than that of defendant and $F_{2}=0$, then plaintiff will spend more money on litigation (other things equal) than will defendant.

PRoOF: This follows directly from the first-order conditions (A2) and (A4) by inverting the $p()$ and $P(\quad)$ functions.

THEOREM 2: If $F_{2}=0$, the marginal productivity of plaintiff is higher than the marginal productivity of defendant, and the rate at which productivity is diminishing is lower for plaintiff than for defendant, then as the level of damages rises plaintiff expenditures will rise more rapidly than will defendant expenditures.

Proof: Totally differentiating the first-order conditions and solving, it follows that $d e^{1} / d D=-p_{1} / D p_{11}$, and $d e^{2} / d D=-P_{2} / D P_{22}$. The statement of the theorem follows directly from the assumptions.

The theorems have been stated in terms of the conditions necessary for plaintiff's expenditures to be higher than defendant's, but the converse could also have been chosen in each case. Notice that once the $F(\quad)$ function is accounted for, defendant's expenditures are more likely to be higher than plaintiff's.

THEOREM 3: Assume that the marginal productivities of defendant and plaintiff are the same, $p_{1}(\quad)=-P_{2}(\quad)$, as are the rates at which the marginal productivities diminish, $p_{11}()=-P_{22}()$. Then if $F_{2}<0$ and $F_{22}>0$, plaintiff expenditures will rise more rapidly than will defendant expenditures as the damage level rises.

Proof: Differentiation of the first-order condition for defendant (A4) yields the following:

$$
\frac{d e^{2}}{d D}=-\frac{P_{2}}{\left(D P_{22}+V F_{22}\right)}
$$

However, from the proof of theorem 2 we see that differentiation of the first-order condition for plaintiff yields

$$
\frac{d e^{1}}{d D}=-\frac{p_{1}}{D p_{11}}
$$

With $p_{1}=-P_{2}, p_{11}=-P_{22}$, and $V>0$, it follows that $d e^{1 / d D}>d e^{2} / d D$.

THEOREM 4: The ratio of plaintiff expenditures to defendant expenditures is likely to rise with damages in the case, $D$, other things equal:

1. if plaintiff's marginal productivity of expenditures is higher than defendant's;

2. if plaintiff's marginal productivity diminishes more slowly than defendant's;

3 . if the discounted present value of future damages is higher; and

4. the greater the responsiveness of the probability of future litigation to an increase in defendant's expenditures.

Proof: Since a set of general conditions illustrating the theorem is somewhat cumbersome, I illustrate the results in a special case. Assume that $p\left(e^{1}\right)=\left(e^{1}\right)^{a}$, $P\left(e^{2}\right)=1-\left(e^{2}\right)^{b}, F\left(e^{2}\right)=1-k\left(e^{2}\right)^{b}$. Then, it is not difficult to show (by solving 
the first-order conditions) that: $\left(e^{1 / /} e^{2}\right)=\left\{(a D)^{1 /(1-a)}\right\} /\left\{[b(D+k V)]^{1 /(1-b)}\right\}$. Differentiating this expression with respect to $D$, it follows that

1. when $a=b$, the ratio of plaintiff to defendant expenditures increases unambiguously with increases in $D$,

2. the same result holds if $a>b$,

3. with $a<b$, and a sufficiently large value of $k V$, the same result holds, and

4. only with $a<b$, and $k V$ sufficiently small, will the ratio of plaintiff to defense expenditures fall with increases in $V$. 
HeinOnline -- 13 J. Legal Stud. 5641984 